\title{
Minimally invasive spine surgery for adult degenerative lumbar scoliosis
}

\author{
Sean Dangelmajer, B.A., ${ }^{1}$ Patricia L. Zadnik, B.A., ${ }^{1}$ Samuel T. Rodriguez, M.D., ${ }^{2}$ \\ Ziya L. Gokaslan, M.D., ${ }^{1}$ and Daniel M. Sciubba, M.D. ${ }^{1}$ \\ ${ }^{1}$ Department of Neurosurgery, The Johns Hopkins University School of Medicine, Baltimore, Maryland; \\ and ${ }^{2}$ Department of Anesthesia, Boston Children's Hospital, Boston, Massachusetts
}

Object. Historically, adult degenerative lumbar scoliosis (DLS) has been treated with multilevel decompression and instrumented fusion to reduce neural compression and stabilize the spinal column. However, due to the profound morbidity associated with complex multilevel surgery, particularly in elderly patients and those with multiple medical comorbidities, minimally invasive surgical approaches have been proposed. The goal of this meta-analysis was to review the differences in patient selection for minimally invasive surgical versus open surgical procedures for adult DLS, and to compare the postoperative outcomes following minimally invasive surgery (MIS) and open surgery.

Methods. In this meta-analysis the authors analyzed the complication rates and the clinical outcomes for patients with adult DLS undergoing complex decompressive procedures with fusion versus minimally invasive surgical approaches. Minimally invasive surgical approaches included decompressive laminectomy, microscopic decompression, lateral and extreme lateral interbody fusion (XLIF), and percutaneous pedicle screw placement for fusion. Mean patient age, complication rates, reoperation rates, Cobb angle, and measures of sagittal balance were investigated and compared between groups.

Results. Twelve studies were identified for comparison in the MIS group, with 8 studies describing the lateral interbody fusion or XLIF and 4 studies describing decompression without fusion. In the decompression MIS group, the mean preoperative Cobb angle was $16.7^{\circ}$ and mean postoperative Cobb angle was $18^{\circ}$. In the XLIF group, mean pre- and postoperative Cobb angles were $22.3^{\circ}$ and $9.2^{\circ}$, respectively. The difference in postoperative Cobb angle was statistically significant between groups on 1-way ANOVA $(\mathrm{p}=0.014)$. Mean preoperative Cobb angle, mean patient age, and complication rate did not differ between the XLIF and decompression groups. Thirty-five studies were identified for inclusion in the open surgery group, with 18 studies describing patients with open fusion without osteotomy and 17 papers detailing outcomes after open fusion with osteotomy. Mean preoperative curve in the open fusion without osteotomy and with osteotomy groups was $41.3^{\circ}$ and $32^{\circ}$, respectively. Mean reoperation rate was significantly higher in the osteotomy group $(\mathrm{p}=0.008)$. On 1 -way ANOVA comparing all groups, there was a statistically significant difference in mean age $(\mathrm{p}=0.004)$ and mean preoperative curve $(\mathrm{p}=0.002)$. There was no statistically significant difference in complication rates between groups $(p=0.28)$.

Conclusions. The results of this study suggest that surgeons are offering patients open surgery or MIS depending on their age and the severity of their deformity. Greater sagittal and coronal correction was noted in the XLIF versus decompression only MIS groups. Larger Cobb angles, greater sagittal imbalance, and higher reoperation rates were found in studies reporting the use of open fusion with osteotomy. Although complication rates did not significantly differ between groups, these data are difficult to interpret given the heterogeneity in reporting complications between studies.

(http://thejns.org/doi/abs/10.3171/2014.3.FOCUS144)

KEY WORDS $\bullet$ adult degenerative lumbar scoliosis $\bullet$ decompression $\bullet$
minimally invasive spine surgery $\bullet$ fusion $\bullet$ laminectomy $\bullet$ foraminotomy
outcomes $\bullet \quad$ meta-analysis

$\mathrm{I}$ $\mathrm{N}$ contrast to juvenile scoliosis, adult degenerative lumbar scoliosis (DLS) is a progressive pathology associated with asymmetrical intervertebral disc degeneration, facet hypertrophy, and progressive loss of lumbar lordosis with increasing deformity in the coronal and sagittal planes and disruption of spinopelvic proportions (Fig. 1A). ${ }^{41}$ Lateral listhesis, rotational deformity, and osteopo-

\footnotetext{
Abbreviations used in this paper: DLS = degenerative lumbar scoliosis; MIS = minimally invasive surgery; ODI = Oswestry Disability Index; XLIF = extreme lateral interbody fusion.
}

rotic vertebral fractures may also contribute to DLS deformity. Patients with DLS often suffer from significant pain or weakness due to nerve root compression that can be a result of the formation of osteophytes, thickening of the ligamentum flavum, cervical spondylosis, degeneration of the lumbar intervertebral discs, and changes in spinal canal morphology such as stenosis (Fig. 1B)..$^{35,40}$

Unlike most adolescents with scoliosis, adult patients with DLS often suffer from additional comorbidities, and are less optimal surgical candidates. Thus, for a subset of DLS patients presenting with predominantly radicular 

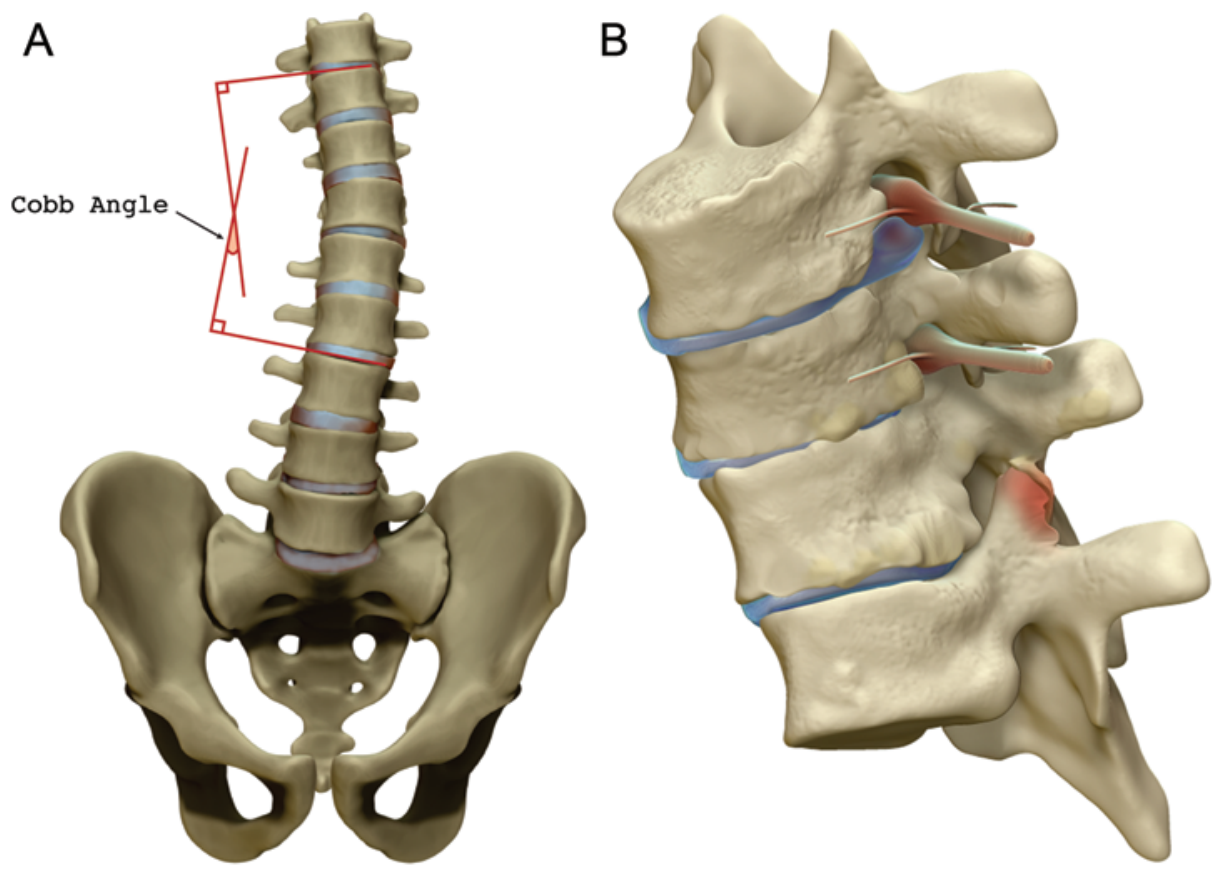

C
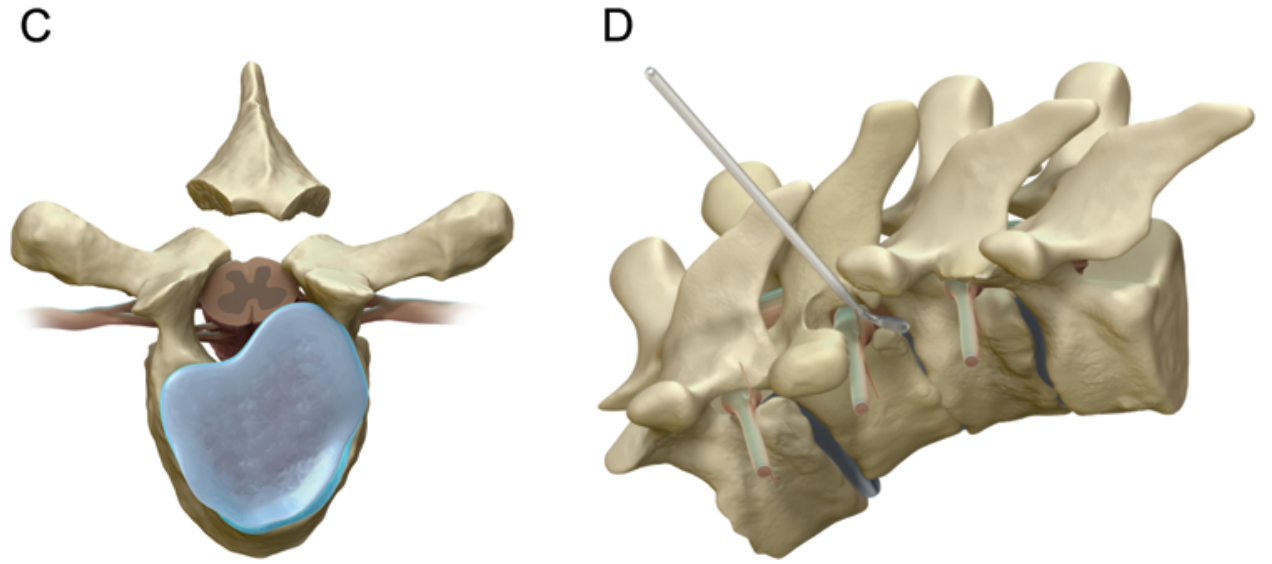

FIG. 1. Illustrations showing the Cobb angle (A), nerve root compression (B), decompressive lumbar laminectomy $(C)$, and lumbar foraminotomy (D). A: The Cobb angle is measured by extending two $90^{\circ}$ angles from the intervertebral discs of the 2 most displaced vertebrae. Adult DLS is defined as a lumbar curve in the coronal plane with a Cobb angle $>10^{\circ}$ without a thoracic curve in an adult (older than 35 years) with no previous history of adolescent scoliosis. B: Nerve root compression can be caused by degeneration of the intervertebral discs, facet hypertrophy, disc herniation, or osteophyte formation. C: Decompressive lumbar laminectomy is a common procedure for patients with DLS or spinal stenosis, in which the lamina is removed to provide adequate space for the exiting nerve roots. D: Removing portions of the foramen by way of microscopic lumbar foraminotomy can provide adequate pain relief for patients with degenerative lumbar foraminal stenosis. Copyright Samuel T. Rodriguez. Published with permission.

symptoms from isolated unilateral nerve root compression, minimally invasive approaches have been proposed as a surgical solution to reduce the morbidity associated with complex multilevel procedures. . $8,36,51^{2}$

In patients with DLS, decompressive laminectomy alone or with foraminotomy may be considered as a conservative treatment strategy, as it relieves the symptoms without addressing the overall sagittal imbalance, lateral listhesis, or coronal deformity. For elderly patients, this approach provides symptom relief without the risks of major surgery. Following decompressive laminectomy, a subset of patients may experience mechanical instability and recurrent radiculopathy. ${ }^{5}$ Fusion with posterior mul- tilevel pedicle screw placement has become common for DLS patients with malalignment and mechanical instability. ${ }^{27,16-18,21,25,29-31,33,35,39,45,46,48,49,52}$ Despite its advantages, decompression with fusion involves risks such as adjacent-segment disease, instrumentation failure (especially in patients with osteoporosis), and infection. ${ }^{51}$ Traditional open fusion techniques are typically performed using a long midline incision, exposing patients to a greater risk of wound breakdown and infection. Percutaneous pedicle screw placement is an alternative approach that provides the benefits of fusion without requiring a large incision, potentially reducing the likelihood of postoperative complications. 


\section{Meta-analysis of outcomes associated with MIS for adult DLS}

Another minimally invasive approach, extreme lateral interbody fusion (XLIF), may be used to restore disc height in patients with asymmetrical disc degeneration in DLS. 3,4,13,19,25-27 This approach reduces disruption of the deep paraspinal musculature, reducing postoperative pain and morbidity. The XLIF approach allows access to anterior pathologies without a traditional anterior approach, reducing risk to the bowel and other visceral structures. However, this approach is often used in combination with open fusion procedures, increasing patient exposure to open surgical risks. ${ }^{25}$

A patient's global spinal alignment further determines the surgical approach for DLS. Spinopelvic parameters such as lumbar lordosis, sagittal vertical axis, pelvic tilt, and pelvic incidence can be disrupted in patients with DLS, requiring surgical correction. Osteotomies are often used to restore lumbar lordosis and correct the overall sagittal balance for patients with DLS.1,6,8$12,14,15,20,22,23,32,34,37,38,42$ Posterior fusion is often used following osteotomies.

In some instances, minimally invasive decompression may be all that is necessary to provide adequate pain relief. ${ }^{24,35,43,44,46}$ Previous studies have indicated that laminectomies (Fig. 1C) can cause impairment of the facet joints, resulting in segmental instability. ${ }^{36}$ There is evidence to support the belief that good clinical outcomes can be achieved following minimally invasive decompression without causing significant postoperative instability. Microscopic bilateral decompression via a unilateral approach is a minimally invasive technique that has been shown to produce positive postoperative clinical outcomes while reducing postoperative instability. ${ }^{36}$ Foraminotomy (Fig. 1D) is another minimally invasive decompressive technique in which portions of the foramen are removed, relieving the exiting nerve root from compression. Despite positive clinical outcomes associated with minimally invasive techniques for the treatment of DLS, fusion has become more prevalent in the past 2 decades as an adjunct to decompressive techniques in an effort to provide additional spinal stability.

The goal of this meta-analysis is to review the outcomes following minimally invasive and conservative treatments for DLS, including decompression, foraminotomy, XLIF, and percutaneous pedicle screw placement. In addition, we will compare the minimally invasive surgery (MIS) data to the current literature reporting outcomes following the traditional open approach to DLS, including open fusion and osteotomy.

\section{Methods}

A query of the PubMed database was performed to identify articles pertaining to this study. Search criteria for inclusion in the MIS group included studies in English, published since 1980, with full text available, in human subjects, involving a patient cohort of more than 10 patients with adult DLS who underwent operative intervention without fusion. Exclusion criteria for the MIS group included studies with adolescent patients, fusiononly cohorts, non-English studies, and studies without full text available. Key words used in the search were "degenerative lumbar scoliosis AND adult AND decompression" and "minimally invasive AND scoliosis." The results of this search are summarized in Table 1.

Search criteria for inclusion in the open surgical group included an adult cohort with DLS greater than or equal to 10 patients, full text available, studies in English, with documented complication rates for adult DLS patients, using the search terms "degenerative lumbar scoliosis AND adult AND fusion." Exclusion criteria for the fusion group included studies with adolescent patients, mean patient age less than 40 years, less than 24 months of clinical follow-up, non-English articles, and studies without full text available. The results from this group are summarized in Tables 2 and 3.

Patient sample size reflects the number of patients within the study undergoing the surgical procedure of interest. The quality of the evidence was classified using the US Preventive Services Task Force system for ranking levels of evidence. Complication data were not reported in a uniform manner for all studies. The reported complication rates in Tables 1-3 were calculated using the absolute number of complications divided by the number of patients reported in the study. Oswestry Disability Index (ODI) data were reported as the absolute change between the preoperative and postoperative scores on the raw scale. Sagittal imbalance was defined as the horizontal distance from the anterior aspect of S-1 to the C-7 plumb line. Osteotomy includes pedicle subtraction osteotomy, vertebral column resection, or Smith-Petersen osteotomy. Mean preoperative curve describes the coronal Cobb angle. Descriptive statistics were calculated using Microsoft Excel version 2010. One-way ANOVA was calculated using the ANOVA Calculator for One-Way ANOVA from summary data (http://www.danielsoper.com/statcalc3/). The threshold for statistical significance was set at $\mathrm{p}<$ 0.05 .

\section{Results}

\section{Minimally Invasive Approach}

XLIF Studies. Minimally invasive studies were grouped into XLIF versus decompression groups. Among studies using the XLIF technique $(n=8)$, the mean patient age was 64.5 years (range 56-68.4 years), and the mean follow-up was 17.4 months (range 11-24 months). The mean preoperative Cobb angle measuring coronal scoliosis was $22.3^{\circ}$ (range $13^{\circ}-31.4^{\circ}$ ). The mean postoperative Cobb angle was $9.2^{\circ}$ (range $6.2^{\circ}-14^{\circ}$; Table 1 ). Among studies reporting patient outcomes related to lumbar lordosis and sagittal angle $(n=5), 2$ studies reported an increase in lumbar lordosis..$^{13,47}$ Dakwar and colleagues reported that two-thirds of patients had a corrected sagittal imbalance with XLIF, and Karikari and colleagues reported an increased postoperative sagittal angle. ${ }^{19,27}$ Johnson et al. reported no change in lumbar lordosis following XLIF. ${ }^{26}$ The mean complication rate for MIS XLIF studies was $18.7 \%$ (range $0-30 \%$ ) and mean ODI improvement was 21.45 (range 8-32.1; Table 1).

Decompression Studies. Among studies in the minimally invasive decompression group $(n=4)$, mean patient 
S. Dangelmajer et al.

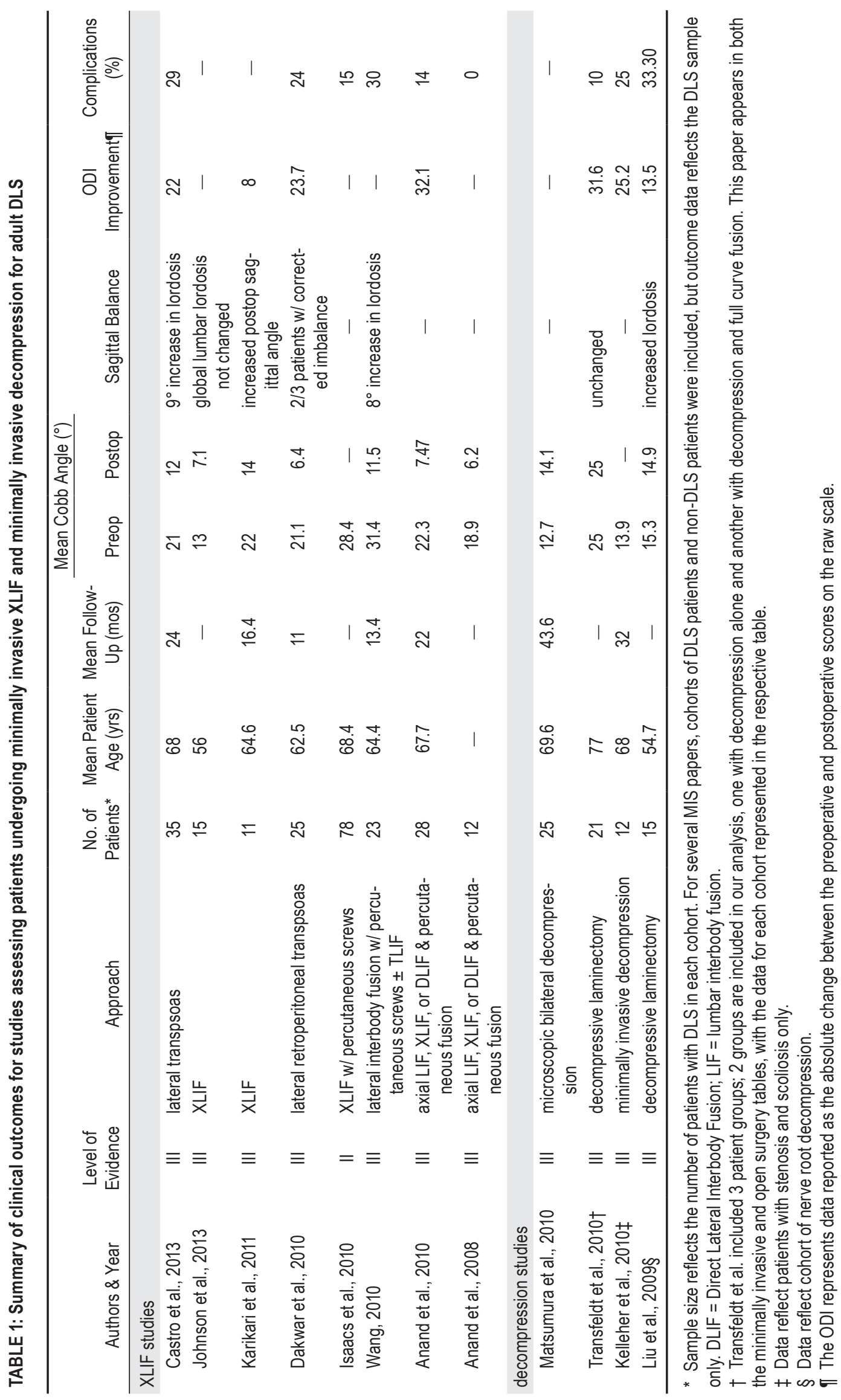


Meta-analysis of outcomes associated with MIS for adult DLS

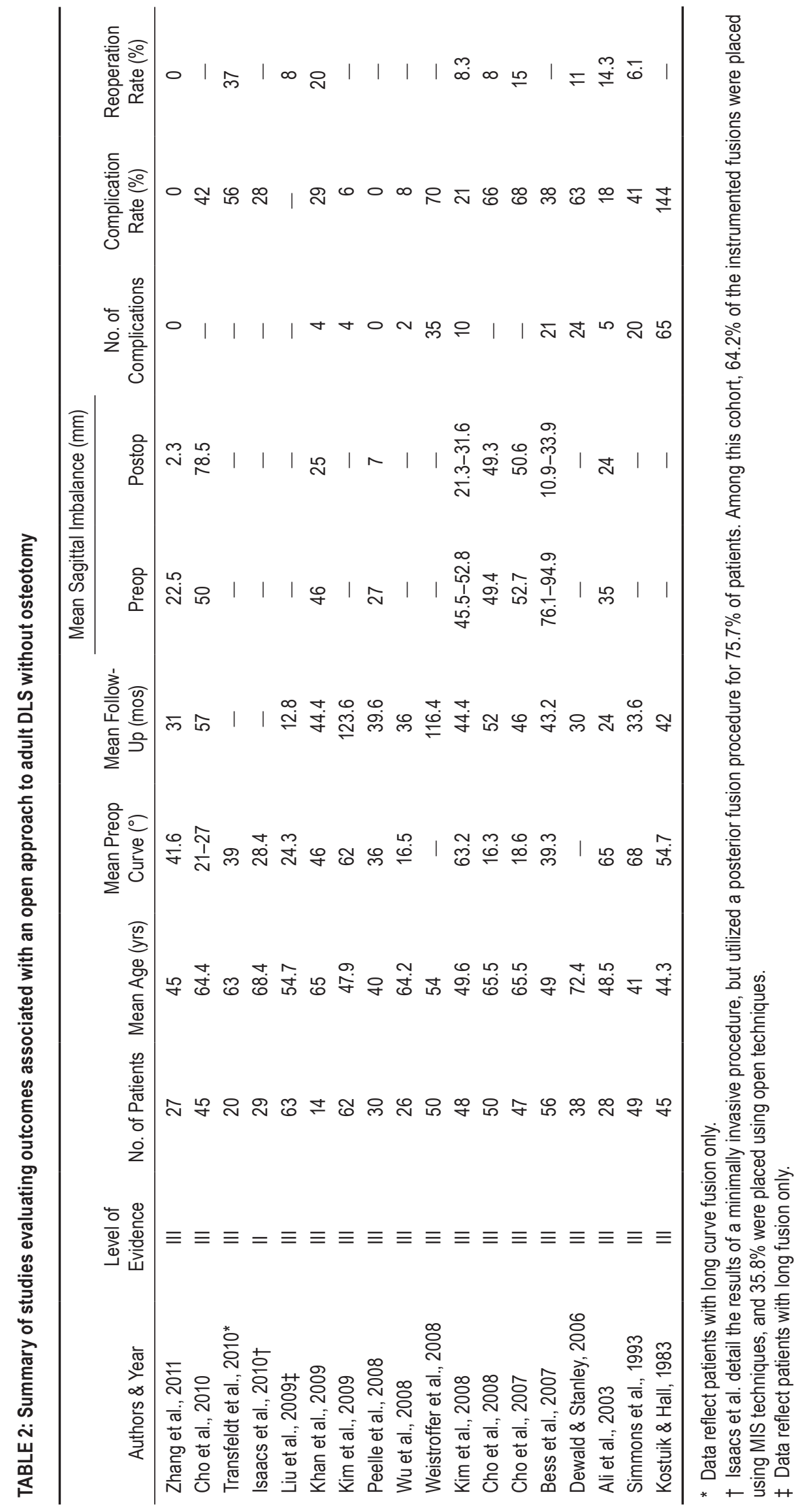


S. Dangelmajer et al.

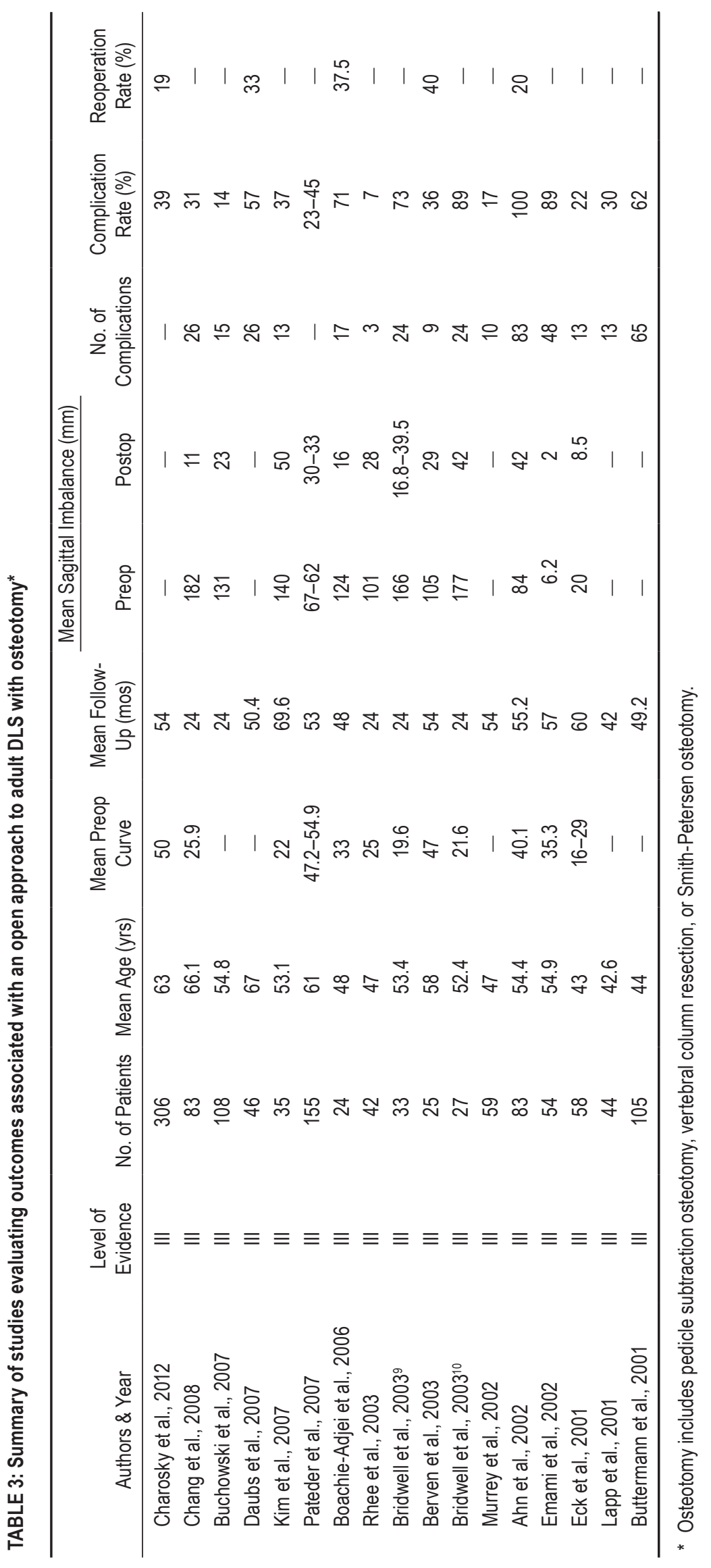




\section{Meta-analysis of outcomes associated with MIS for adult DLS}

age was 67.3 years (range 54.7-77 years) and mean follow-up was 37.8 months (range 32-43.6 months; Table 1). Mean preoperative Cobb angle measuring coronal scoliosis was $16.7^{\circ}$ (range $12.7^{\circ}-25^{\circ}$ ) and mean postoperative Cobb angle was $18^{\circ}$ (range $14.1^{\circ}-25^{\circ}$ ). Among studies reporting patient outcomes related to lumbar lordosis (n $=2$ ), Liu et al. reported an increased lordosis with decompressive laminectomy and Transfeldt and colleagues reported no change in spinopelvic proportions with the same procedure (Table 1) ${ }^{35,46}$ Mean complication rate for the minimally invasive decompression group was $22.8 \%$ (range 10\%-33.3\%) and mean ODI improvement was 23.4 (range 13.5-25.2; Table 1).

Using 1-way ANOVA, there was no statistically significant difference between the XLIF or decompression minimally invasive groups when comparing age $(\mathrm{p}=$ $0.39)$, complication rate $(\mathrm{p}=0.647)$, or preoperative Cobb angle $(\mathrm{p}=0.089)$. The mean postoperative Cobb angle was significantly different between the XLIF and decompression groups $(\mathrm{p}=0.014)$; the mean postoperative $\mathrm{Cobb}$ angle was larger in the decompression group $\left(18^{\circ}\right)$ than in the XLIF group $\left(9.2^{\circ}\right.$; Table 1$)$.

\section{Traditional Open Approach}

Open Approach Without Osteotomy. Studies reviewing outcomes following the traditional open approach were grouped into studies using open fusion without osteotomy (Table 2) or with osteotomy (Table 3). Among studies reporting patient outcomes following open surgery for DLS without osteotomy $(\mathrm{n}=18)$, mean patient age was 55.7 years (range $40-72.4$ years). The mean preoperative curve was $41.3^{\circ}$ (range $16.3^{\circ}-68^{\circ}$ ). The mean complication rate was $41.1 \%$ (range $0 \%-144 \%$ ), when the absolute number of complications was counted. The mean reoperation rate was $12.8 \%$ (range 0\%-37\%; Table 2). Mean preoperative sagittal imbalance ranged from $22.5 \mathrm{~mm}$ to $94.9 \mathrm{~mm}$, whereas mean postoperative sagittal imbalance ranged from $2.3 \mathrm{~mm}$ to $78.5 \mathrm{~mm}$.

Open Approach With Osteotomy. Among studies reporting an open surgical technique with osteotomy (including pedicle subtraction osteotomy, vertebrectomy, or Smith-Petersen osteotomy; $\mathrm{n}=17$ ), the mean patient age was 53.5 years (range $42.6-67$ years; Table 3 ). The mean preoperative curve was $32^{\circ}$ (range $16^{\circ}-54.9^{\circ}$ ), the mean complication rate was $48.4 \%$ (range $7 \%-100 \%$ ), and the mean reoperation rate was $29.9 \%$ (range $19 \%-40 \%$ ). The mean preoperative sagittal imbalance ranged from 6.2 $\mathrm{mm}$ to $182 \mathrm{~mm}$, whereas mean postoperative sagittal imbalance ranged from $2 \mathrm{~mm}$ to $50 \mathrm{~mm}$ (Table 3 ).

Using 1-way ANOVA, there was no statistically significant difference between patients in the open surgery without osteotomy group versus the osteotomy group in mean age $(p=0.35)$ or mean complication rate $(p=0.65)$. There was a significant difference in mean reoperation rate $(\mathrm{p}=0.008)$.

\section{Minimally Invasive Versus Open Approach}

Using 1-way ANOVA, there was a statistically significant difference between groups (MIS XLIF, MIS de- compression, open without osteotomy, and open with osteotomy) in mean age $(\mathrm{p}=0.004)$ and mean preoperative curve $(\mathrm{p}=0.002)$. There was no statistically significant difference in complication rates between groups using a 1-way ANOVA $(\mathrm{p}=0.28)$.

\section{Discussion}

This meta-analysis of the adult DLS literature strongly suggests that the patient populations undergoing MIS are significantly different in age and severity of deformity compared with patients undergoing open surgery. While complications did not significantly differ between the MIS and open surgery groups, there was a significant difference in patient age between groups in this study. With increasing age, patients are more likely to have poor bone quality and additional comorbidities. Furthermore, within each study there was variability in what constituted a complication. In some studies, the only complications reported were "major," 25 while in others, any patient complication was counted toward the total number of complication events. ${ }^{33}$ Given the variability in what constituted a complication and the significantly different patient ages between groups, it is unclear how to interpret the complications data.

Minimally invasive surgery for adult DLS provided deformity correction in the sagittal and coronal planes, with the greatest changes observed in patients undergoing the XLIF procedure. As the XLIF data suggest, this MIS procedure for DLS resulted in some restoration of lumbar lordosis. ${ }^{13,19,47}$ Furthermore, although the mean preoperative Cobb angle did not differ between the XLIF and decompression MIS groups $\left(22.3^{\circ}\right.$ vs $16.7^{\circ}$, respectively) the postoperative $\mathrm{Cobb}$ angle was significantly different for XLIF versus decompression $\left(9.2^{\circ}\right.$ vs $18^{\circ}$, respectively). The postoperative Cobb angle actually increased for the decompression group $\left(16.7^{\circ}\right.$ to $\left.18^{\circ}\right)$. Some evidence suggests that this increase in postoperative Cobb angle portends a future increase in the patient's deformity. Matsumura and colleagues analyzed the clinical outcomes for 50 patients undergoing microscopic bilateral decompression via a unilateral approach for treatment of DLS without instability. ${ }^{36}$ They concluded that patients had a postoperative increase in Cobb angle (approximately $2^{\circ}$ ) and worsening of postoperative Cobb angle progression when there was less facet joint preservation. ${ }^{36}$ Clinically, the ODI improvement was larger in the decompression group (23.4) versus the XLIF group (21.5), so it is unclear how to interpret the increase in Cobb angle. Future longterm studies are needed to monitor deformity progression in patients after MIS for adult DLS.

Case series data suggest the benefits of decompression without fusion provided patients with durable symptom relief. Silvers et al. specifically investigated outcomes following decompressive laminectomy for patients with DLS. ${ }^{44}$ Two hundred fifty-eight patients were included, 12 of whom had DLS. The mean age of the 12 patients undergoing laminectomy for DLS was 69 years, and there was a $100 \%$ relief in pain and $100 \%$ return to normal activity reported in the short-term follow-up (mean 8.4 months). ${ }^{44}$ The short-term outcome reported that $93 \%$ of the patients 


\section{S. Dangelmajer et al.}

had pain relief and $95 \%$ of the patients returned to normal activity, whereas in the long-term (4.7 years) there was $75 \%$ patient satisfaction, $64 \%$ with pain relief, and $56 \%$ with activity return. These investigators concluded that decompressive lumbar laminectomy is safe with a high medium-to-long-term success rate. ${ }^{44}$ These results were further supported by San Martino et al. in a study of 20 patients with DLS undergoing laminectomy with no fusion. ${ }^{43}$ There were no reoperations needed and all patients experienced relief of their chief complaint, with restoration of function following decompression. ${ }^{43}$

Within several studies, minimally invasive and conservative techniques demonstrated lower complication rates compared with matched open fusion cohorts. ${ }^{35,46}$ Transfeldt and colleagues conducted a study including 85 patients, 21 of whom underwent decompression alone. Patient outcomes were compared for decompression alone, long fusion, and short fusion. The decompression alone group had a $10 \%$ complication rate compared with $56 \%$ for long fusion and $40 \%$ for short fusion. ${ }^{46}$ Liu et al. investigated the outcomes of 112 patients with DLS undergoing either decompression alone, or decompression with either short or long fusion with Cobb angles ranging from $10^{\circ}$ to $46^{\circ}$. Patients who underwent multisegment fusion (>3 segments) had greater improvement in lordosis angle and Cobb angle compared with the decompression alone patients. ${ }^{35}$ Cho et al. performed a study examining complications following short fusion versus long fusion for DLS. ${ }^{18}$ It was found that short fusion was sufficient for patients with small Cobb angles $\left(<25^{\circ}\right)$ and good spinal balance, while patients with a severe Cobb angle and rotatory subluxation require long fusion to decrease the risk of adjacent-segment disease. Long fusion was associated with an increase in early perioperative complications. ${ }^{18}$ A previous study conducted by the same author assessed complications in patients undergoing posterior fusion with instrumentation and found that the complication rate was $68 \%$, citing abundant blood loss as a significant risk factor for early perioperative complications. ${ }^{17}$ However, the mean reoperation rate was $12.8 \%$ in the open fusion group $^{2,17,18,21,29,31,35,45,46,52}$ compared with $22.8 \%$ for minimally invasive decompression surgeries. ${ }^{28,35,36,46,51}$

The direct comparison of open fusion versus percutaneous fusion was observed in the prospective, nonrandomized, multicenter evaluation of the XLIF procedure with fusion by Isaacs and colleagues. ${ }^{25}$ In this study, the authors reported an overall major complication rate of $12.2 \%$, with a lower major complication rate for patients undergoing XLIF alone or percutaneous instrumentation $(9 \%) .{ }^{25}$ Higher major complication rates were noted for patients with open posterior instrumentation (20.7\%). ${ }^{25}$ While $64.2 \%$ of patients had pedicle screw placement using minimal access surgical techniques, $35.8 \%$ of patients included in the study had open fusion using standard open techniques. ${ }^{25}$ The heterogeneity within this sample highlights the difficulty in interpreting results from the MIS and open surgery literature. While the XLIF and percutaneous pedicle screw placement are MIS techniques, how do we interpret patient outcomes with combined MIS and open surgical procedures?

In this meta-analysis of the open surgery literature, open fusion with osteotomy demonstrated a greater reoperation rate $(30 \%)$ compared with open fusion without osteotomy (12.8\%), although patient age and complication rate did not differ significantly. Although data on the preoperative sagittal imbalance were not directly compared due to variability in the samples and the more consistent reporting of sagittal imbalance in the osteotomy literature, patients in the osteotomy group consistently reported sagittal imbalance greater than $10 \mathrm{~cm}$ (Table 3). These patients had larger deformities and required more correction; thus, the difference in reoperation rate is not surprising.

There are limitations to this study. This is a literature review of retrospectively collected patient data. As such, there was considerable heterogeneity in the patient samples for each study. Although the inclusion criteria were standardized for selection in this literature review, the focus of each study varied. Of note, among the minimally invasive studies, there was considerable variation in the technique used, and the inclusion of studies with percutaneous fusion added additional variance to the sample. The authors attempted to control for this variation by separating the statistical analysis within the MIS group to decompression only and XLIF with or without percutaneous fusion. A thorough review of outcomes after surgery for adult DLS was completed by Yadla and colleagues in 2010, which concluded with a statement that standardization is needed in reporting outcomes following surgery. ${ }^{50}$

\section{Conclusions}

The results of this study suggest that surgeons are selecting patients for open surgery who are younger and have a larger preoperative coronal scoliosis. This review also suggests that a greater change in sagittal balance can be achieved using open techniques; however, data from several MIS studies using the XLIF technique suggest that a restoration of lumbar lordosis is possible with XLIF. Furthermore, on closer review of the individual studies, MIS techniques have demonstrated considerable improvement in patient outcome and may be appropriate for older patients with smaller coronal scoliosis in whom sagittal correction is not necessary.

\section{Disclosure}

Dr. Sciubba serves as a consultant to DePuy, Medtronic, Globus, and NuVasive.

Author contributions to the study and manuscript preparation include the following. Conception and design: Sciubba, Gokaslan. Acquisition of data: Dangelmajer, Zadnik. Analysis and interpretation of data: Dangelmajer, Zadnik. Drafting the article: Dangelmajer, Rodriguez. Critically revising the article: Sciubba, Zadnik. Reviewed submitted version of manuscript: all authors. Approved the final version of the manuscript on behalf of all authors: Sciubba. Administrative/technical/material support: Rodriguez. Study supervision: Sciubba, Gokaslan.

\section{References}

1. Ahn UM, Ahn NU, Buchowski JM, Kebaish KM, Lee JH, Song ES, et al: Functional outcome and radiographic correction after spinal osteotomy. Spine (Phila Pa 1976) 27:13031311,2002 


\section{Meta-analysis of outcomes associated with MIS for adult DLS}

2. Ali RM, Boachie-Adjei O, Rawlins BA: Functional and radiographic outcomes after surgery for adult scoliosis using third-generation instrumentation techniques. Spine (Phila Pa 1976) 28:1163-1170, 2003

3. Anand N, Baron EM, Thaiyananthan G, Khalsa K, Goldstein TB: Minimally invasive multilevel percutaneous correction and fusion for adult lumbar degenerative scoliosis: a technique and feasibility study. J Spinal Disord Tech 21:459-467, 2008

4. Anand N, Rosemann R, Khalsa B, Baron EM: Mid-term to long-term clinical and functional outcomes of minimally invasive correction and fusion for adults with scoliosis. Neurosurg Focus 28(3):E6, 2010

5. Benner B, Ehni G: Degenerative lumbar scoliosis. Spine (Phila Pa 1976) 4:548-552, 1979

6. Berven SH, Deviren V, Smith JA, Hu SH, Bradford DS: Management of fixed sagittal plane deformity: outcome of combined anterior and posterior surgery. Spine (Phila Pa 1976) 28:1710-1716, 2003

7. Bess RS, Lenke LG, Bridwell KH, Cheh G, Mandel S, Sides B: Comparison of thoracic pedicle screw to hook instrumentation for the treatment of adult spinal deformity. Spine (Phila Pa 1976) 32:555-561, 2007

8. Boachie-Adjei O, Ferguson JA, Pigeon RG, Peskin MR: Transpedicular lumbar wedge resection osteotomy for fixed sagittal imbalance: surgical technique and early results. Spine (Phila Pa 1976) 31:485-492, 2006

9. Bridwell KH, Lewis SJ, Edwards C, Lenke LG, Iffrig TM, Berra A, et al: Complications and outcomes of pedicle subtraction osteotomies for fixed sagittal imbalance. Spine (Phila Pa 1976) 28:2093-2101, 2003

10. Bridwell KH, Lewis SJ, Lenke LG, Baldus C, Blanke K: Pedicle subtraction osteotomy for the treatment of fixed sagittal imbalance. J Bone Joint Surg Am 85-A:454-463, 2003

11. Buchowski JM, Bridwell KH, Lenke LG, Kuhns CA, Lehman RA Jr, Kim YJ, et al: Neurologic complications of lumbar pedicle subtraction osteotomy: a 10-year assessment. Spine (Phila Pa 1976) 32:2245-2252, 2007

12. Buttermann GR, Glazer PA, Hu SS, Bradford DS: Anterior and posterior allografts in symptomatic thoracolumbar deformity. J Spinal Disord 14:54-66, 2001

13. Castro C, Oliveira L, Amaral R, Marchi L, Pimenta L: Is the lateral transpsoas approach feasible for the treatment of adult degenerative scoliosis? Clin Orthop Relat Res [epub ahead of print], 2013

14. Chang KW, Cheng CW, Chen HC, Chang KI, Chen TC: Closing-opening wedge osteotomy for the treatment of sagittal imbalance. Spine (Phila Pa 1976) 33:1470-1477, 2008

15. Charosky S, Guigui P, Blamoutier A, Roussouly P, Chopin D, Study Group on Scoliosis: Complications and risk factors of primary adult scoliosis surgery: a multicenter study of 306 patients. Spine (Phila Pa 1976) 37:693-700, 2012

16. Cho KJ, Suk SI, Park SR, Kim JH, Kang SB, Kim HS, et al: Risk factors of sagittal decompensation after long posterior instrumentation and fusion for degenerative lumbar scoliosis. Spine (Phila Pa 1976) 35:1595-1601, 2010

17. Cho KJ, Suk SI, Park SR, Kim JH, Kim SS, Choi WK, et al: Complications in posterior fusion and instrumentation for degenerative lumbar scoliosis. Spine (Phila Pa 1976) 32:22322237, 2007

18. Cho KJ, Suk SI, Park SR, Kim JH, Kim SS, Lee TJ, et al: Short fusion versus long fusion for degenerative lumbar scoliosis. Eur Spine J 17:650-656, 2008

19. Dakwar E, Cardona RF, Smith DA, Uribe JS: Early outcomes and safety of the minimally invasive, lateral retroperitoneal transpsoas approach for adult degenerative scoliosis. Neurosurg Focus 28(3):E8, 2010

20. Daubs MD, Lenke LG, Cheh G, Stobbs G, Bridwell KH: Adult spinal deformity surgery: complications and outcomes in patients over age 60. Spine (Phila Pa 1976) 32:2238-2244, 2007
21. DeWald CJ, Stanley T: Instrumentation-related complications of multilevel fusions for adult spinal deformity patients over age 65: surgical considerations and treatment options in patients with poor bone quality. Spine (Phila Pa 1976) 31 (19 Suppl):S144-S151, 2006

22. Eck KR, Bridwell KH, Ungacta FF, Riew KD, Lapp MA, Lenke LG, et al: Complications and results of long adult deformity fusions down to 14, 15, and the sacrum. Spine (Phila Pa 1976) 26:E182-E192, 2001

23. Emami A, Deviren V, Berven S, Smith JA, Hu SS, Bradford DS: Outcome and complications of long fusions to the sacrum in adult spine deformity: luque-galveston, combined iliac and sacral screws, and sacral fixation. Spine (Phila Pa 1976) 27: 776-786, 2002

24. Frazier DD, Lipson SJ, Fossel AH, Katz JN: Associations between spinal deformity and outcomes after decompression for spinal stenosis. Spine (Phila Pa 1976) 22:2025-2029, 1997

25. Isaacs RE, Hyde J, Goodrich JA, Rodgers WB, Phillips FM: A prospective, nonrandomized, multicenter evaluation of extreme lateral interbody fusion for the treatment of adult degenerative scoliosis: perioperative outcomes and complications. Spine 35 (Phila Pa 1976) (26 Suppl):S322-S330, 2010

26. Johnson RD, Valore A, Villaminar A, Comisso M, Balsano M: Pelvic parameters of sagittal balance in extreme lateral interbody fusion for degenerative lumbar disc disease. J Clin Neurosci 20:576-581, 2013

27. Karikari IO, Nimjee SM, Hardin CA, Hughes BD, Hodges TR, Mehta AI, et al: Extreme lateral interbody fusion approach for isolated thoracic and thoracolumbar spine diseases: initial clinical experience and early outcomes. J Spinal Disord Tech 24:368-375, 2011

28. Kelleher MO, Timlin M, Persaud O, Rampersaud YR: Success and failure of minimally invasive decompression for focal lumbar spinal stenosis in patients with and without deformity. Spine (Phila Pa 1976) 35:E981-E987, 2010

29. Khan SN, Hofer MA, Gupta MC: Lumbar degenerative scoliosis: outcomes of combined anterior and posterior pelvis surgery with minimum 2-year follow-up. Orthopedics 32:258, 2009

30. Kim YB, Lenke LG, Kim YJ, Kim YW, Blanke K, Stobbs G, et al: The morbidity of an anterior thoracolumbar approach: adult spinal deformity patients with greater than five-year follow-up. Spine (Phila Pa 1976) 34:822-826, 2009

31. Kim YB, Lenke LG, Kim YJ, Kim YW, Bridwell KH, Stobbs G: Surgical treatment of adult scoliosis: is anterior apical release and fusion necessary for the lumbar curve? Spine (Phila Pa 1976) 33:1125-1132, 2008

32. Kim YJ, Bridwell KH, Lenke LG, Cheh G, Baldus C: Results of lumbar pedicle subtraction osteotomies for fixed sagittal imbalance: a minimum 5-year follow-up study. Spine (Phila Pa 1976) 32:2189-2197, 2007

33. Kostuik JP, Hall BB: Spinal fusions to the sacrum in adults with scoliosis. Spine (Phila Pa 1976) 8:489-500, 1983

34. Lapp MA, Bridwell KH, Lenke LG, Riew KD, Linville DA, Eck KR, et al: Long-term complications in adult spinal deformity patients having combined surgery a comparison of primary to revision patients. Spine (Phila Pa 1976) 26:973-983, 2001

35. Liu W, Chen XS, Jia LS, Song DW: The clinical features and surgical treatment of degenerative lumbar scoliosis: a review of 112 patients. Orthop Surg 1:176-183, 2009

36. Matsumura A, Namikawa T, Terai H, Tsujio T, Suzuki A, Dozono S, et al: The influence of approach side on facet preservation in microscopic bilateral decompression via a unilateral approach for degenerative lumbar scoliosis. Clinical article. J Neurosurg Spine 13:758-765, 2010

37. Murrey DB, Brigham CD, Kiebzak GM, Finger F, Chewning SJ: Transpedicular decompression and pedicle subtraction osteotomy (eggshell procedure): a retrospective review of 59 patients. Spine (Phila Pa 1976) 27:2338-2345, 2002 


\section{S. Dangelmajer et al.}

38. Pateder DB, Kebaish KM, Cascio BM, Neubaeur P, Matusz DM, Kostuik JP: Posterior only versus combined anterior and posterior approaches to lumbar scoliosis in adults: a radiographic analysis. Spine (Phila Pa 1976) 32:1551-1554, 2007

39. Peelle MW, Boachie-Adjei O, Charles G, Kanazawa Y, Mesfin A: Lumbar curve response to selective thoracic fusion in adult idiopathic scoliosis. Spine J 8:897-903, 2008

40. Ploumis A, Transfeldt EE, Gilbert TJ Jr, Mehbod AA, Dykes DC, Perra JE: Degenerative lumbar scoliosis: radiographic correlation of lateral rotatory olisthesis with neural canal dimensions. Spine (Phila Pa 1976) 31:2353-2358, 2006

41. Pritchett JW, Bortel DT: Degenerative symptomatic lumbar scoliosis. Spine (Phila Pa 1976) 18:700-703, 1993

42. Rhee JM, Bridwell KH, Lenke LG, Baldus C, Blanke K, Edwards C, et al: Staged posterior surgery for severe adult spinal deformity. Spine (Phila Pa 1976) 28:2116-2121, 2003

43. San Martino A, D'Andria FM, San Martino C: The surgical treatment of nerve root compression caused by scoliosis of the lumbar spine. Spine (Phila Pa 1976) 8:261-265, 1983

44. Silvers HR, Lewis PJ, Asch HL: Decompressive lumbar laminectomy for spinal stenosis. J Neurosurg 78:695-701, 1993

45. Simmons ED Jr, Kowalski JM, Simmons EH: The results of surgical treatment for adult scoliosis. Spine (Phila Pa 1976) 18:718-724, 1993

46. Transfeldt EE, Topp R, Mehbod AA, Winter RB: Surgical outcomes of decompression, decompression with limited fusion, and decompression with full curve fusion for degenerative scoliosis with radiculopathy. Spine (Phila Pa 1976) 35: 1872-1875, 2010

47. Wang MY, Mummaneni PV: Minimally invasive surgery for thoracolumbar spinal deformity: initial clinical experience with clinical and radiographic outcomes. Neurosurg Focus 28(3):E9, 2010
48. Weistroffer JK, Perra JH, Lonstein JE, Schwender JD, Garvey TA, Transfeldt EE, et al: Complications in long fusions to the sacrum for adult scoliosis: minimum five-year analysis of fifty patients. Spine (Phila Pa 1976) 33:1478-1483, 2008

49. Wu CH, Wong CB, Chen LH, Niu CC, Tsai TT, Chen WJ: Instrumented posterior lumbar interbody fusion for patients with degenerative lumbar scoliosis. J Spinal Disord Tech 21: 310-315, 2008

50. Yadla S, Maltenfort MG, Ratliff JK, Harrop JS: Adult scoliosis surgery outcomes: a systematic review. Neurosurg Focus 28(3):E3, 2010

51. Yamada K, Matsuda H, Nabeta M, Habunaga H, Suzuki A, Nakamura H: Clinical outcomes of microscopic decompression for degenerative lumbar foraminal stenosis: a comparison between patients with and without degenerative lumbar scoliosis. Eur Spine J 20:947-953, 2011

52. Zhang H, Gao Q, Wang Y, Liu S, Guo C, Tang M, et al: Clinical evaluation of indirect decompression treatments for degenerative adult idiopathic scoliosis. Arch Orthop Trauma Surg 131:1639-1647, 2011

Manuscript submitted January 3, 2014.

Accepted March 5, 2014.

Please include this information when citing this paper: DOI: 10.3171/2014.3.FOCUS144.

Address correspondence to: Daniel M. Sciubba, M.D., Department of Neurosurgery, The Johns Hopkins Hospital, Meyer 5-185, 600 N. Wolfe St., Baltimore, MD 21287. email: dsciubb1@jhmi. edu. 